\title{
Comparison of chlorophyll far-red and red fluorescence excitation spectra with photosynthetic oxygen action spectra for photosystem II in algae
}

\author{
Amir Neori ${ }^{1, *}$, Maria Vernet ${ }^{2}$, Osmund Holm-Hansen ${ }^{1, * *}$, Francis T. Haxo ${ }^{2}$ \\ ${ }^{1}$ Food Chain Research Group, A-018, Scripps Institution of Oceanography, University of California, San Diego, La Jolla, \\ California 92093, USA \\ ${ }^{2}$ Marine Biology Research Division, A-002, Scripps Institution of Oceanography, University of California, San Diego, La Jolla, \\ California 92093, USA
}

\begin{abstract}
The shapes of excitation spectra for chlorophyll a fluorescence in the far-red (730 nm) were compared under physiological conditions to those for chlorophyll a fluorescence in the red (685 nm) and to action spectra for photosynthetic oxygen production in diversely pigmented algae. Species examined as representatives of the prominent oceanic light harvesting systems were Chaetoceros gracilis, Glenodinium sp., Ulva sp., Porphyridium cruentum and Chroomonas sp. Qualitatively, for any one alga, all 3 action spectra exhibited broadly similar spectral features, suggesting initial light harvesting for photosynthesis by the same major pigments, i.e. those commonly associated with photosystem II. As such, measurement of $F_{730}$ fluorescence (in preference to $F_{685}$ ) may provide a useful and facile alternative to oxygen action spectra in assessing the full photosynthetic spectral performance $(320$ to $700 \mathrm{~nm}$ ) of individual phytoplankton species or assemblages.
\end{abstract}

\section{INTRODUCTION}

The spectral characteristics of marine algae are important determinants of light attenuation and photosynthesis in the aquatic environment. Spectral absorption properties are largely functions of the kinds, amounts and packaging of pigments present in the algal cell, whereas action spectra reflect fractional absorption and conversion efficiency by photoreactive pigments of the photosynthetic apparatus. Laboratory comparisons of spectral absorption and action spectra for $\mathrm{O}_{2}$ production in different colored algae (for review, see Larkum \& Barrett 1983, Haxo 1985, Lüning \& Dring 1985) have been particularly useful in identifying and evaluating the effectiveness of pigments associated

- Present address: The National Centre for Mariculture, Israel Oceanographic and Limnological Research, POB 1212, Eilat 88112, Israel

- Present address: Polar Research Program, A-002-P, Scripps Institution of Oceanography, University of California, San Diego, La Jolla, California 92093, USA with the $\mathrm{O}_{2}$-evolving system of photosynthesis. Such data are essential for predicting photosynthetic spectral performance in submarine light fields.

Action spectra for chlorophyll a (chl a) fluorescence have been widely used to elucidate the role of accessory pigments in the photosynthetic energy transfer in cultured algae (Dutton et al. 1943, Duysens 1952, Goedheer 1972). Such studies suggested that fluorescence measurements might provide much of the same information as $\mathrm{O}_{2}$ action spectra. In order to document this relationship more closely under physiological conditions, Neori et al. (1986) recently made a detailed wavelength comparison of action spectra for excitation of chl a fluorescence and action spectra for modulated $\mathrm{O}_{2}$ production in algae representing the major oceanic pigment systems. Over the common wavelength interval examined, 390 to $610 \mathrm{~nm}$, the shapes of the excitation spectra for chl a red fluorescence at $685 \mathrm{~nm}\left(\mathrm{~F}_{685}\right)$ and the action spectra for photosystem II (PS II) were in good agreement. The $F_{685}$ measurements could not include the spectral interval 610 to $700 \mathrm{~nm}$ because the fluorescence correction standard commonly employed 
(rhodamine B) cannot be used above $610 \mathrm{~nm}$ (Yguerabide 1968), and also because of the difficulty in blocking the excitation beam when its wavelength approached that of the measured emission at $685 \mathrm{~nm}$. Such considerations have also limited the spectral range in field studies (Yentsch \& Yentsch 1979, Mitchell \& Kiefer 1984). While these difficulties can be minimized with specialized laboratory instrumentation (e.g. Govindjee \& Yang 1966, Owens et al. 1987), such instrumentation is not generally available to the marine biologist, particularly under field conditions.

In order to extend the range of the standard in vivo chl fluorescence technique $\left(\mathrm{F}_{685}\right)$ to include the orange and red regions, it is necessary to compare the far-red band of chl a emission $(F>710)$ with $F_{685}$ emission characteristics as well as with action spectra for modulated oxygen production. In this paper we provide a direct comparison of these methods in a variety of cultured algae having different antenna pigment systems. The comparison also provides a broader base for evaluating the applicability and limitations of fluorescence measurements of algal populations under field conditions, some aspects of which have recently been considered (Neori et al. 1986).

\section{MATERIALS AND METHODS}

Algae. Chaetoceros gracilis (S.I.O. code \# BA. 13; Bacillariophyta) was grown as described previously (Neori et al. 1986) at $60 \mu \mathrm{E} \mathrm{m}^{-2} \mathrm{~s}^{-1}$ to a cell density of $2 \times 10^{5}$ cells $\mathrm{ml}^{-1}$.

Glenodinium sp. (S.I.O. code \# PY 33; Pyrrhophyta) was grown in a $250 \mathrm{ml}$ flask, on a shaker, in $50 \mathrm{ml}$ of GPM medium (Loeblich 1975) at $30 \mu \mathrm{E} \mathrm{m}^{-2} \mathrm{~s}^{-1}$ to a cell density of $3.6 \times 10^{5}$ cells ml ${ }^{-1}$.

Porphyridium cruentum (S.I.O. code \# RH 11; Rhodophyta) was grown in the same medium and under the same conditions as for Glenodinium, to a cell density of $7.2 \times 10^{5}$ cells ml ${ }^{-1}$.

Chroomonas sp. (Provasoli strain; Cryptophyta) was grown as described previously (Neori et al. 1986), at $270 \mu \mathrm{E} \mathrm{m}^{-2} \mathrm{~s}^{-1}$, to a cell density of $7.45 \times 10^{5}$ cells $\mathrm{ml}^{-1}$.

Ulva sp. (probably californica; Chlorophyta) was collected from sides of submerged rocks in a mid-tidal area near La Mission, Baja California. Blades were held for $2 \mathrm{~d}$ at low light in unenriched, flowing filtered seawater prior to the fluorescence and $\mathrm{O}_{2}$ action spectra determinations, which were carried out on the same blade piece.

Photosynthetic action spectra. Action spectra of PS II were measured with a modulated-beam, bare platinum $\mathrm{O}_{2}$ electrode system (Joliot \& Joliot 1968), as modified by Prézelin et al. (1976) and by Neori et al. (1986). The microalgal coverage on the electrode did not exceed 1 cell layer (checked microscopically), thus avoiding mutual shading. Our general experience with this system has been that major features of action spectra for individual species are quite reproducible between repeated scans of the same mount, between aliquots of the same culture (as employed here for Porphyridium cruentum and Chroomonas sp.) and between different batch cultures grown in like manner. In the case of Glenodinium sp. and Chaetoceros gracilis, $\mathrm{O}_{2}$ production and fluorescence action spectra were measured on different batches. Because C. gracilis gave inexplicably noisy $\mathrm{O}_{2}$ signals, an average of 2 rather than a single spectrum was used (Fig. 3).

Fluorescence. All algal samples were pretreated with DCMU (3-[3,4-dichlorophenyl]-1,1-dimethylurea) and fluorescence measured in a Perkin Elmer MPF $44 \mathrm{~A}$ spectrofluorometer as detailed elsewhere (Neori et al. 1984). Except for Chaetoceros gracilis which was thinly dispersed on a glass-fiber filter and the thinbladed macrophyte Ulva sp. which was moist-mounted directly on a holding plate, measurements were made in a $1 \mathrm{~cm}$ cuvette on dilute cell suspensions whose color was barely discernible by eye.

For measurements at $685 \mathrm{~nm}\left(\mathrm{~F}_{685}\right)$ the spectrofluorometer was set in the ratio mode with rhodamine $B$ in the reference compartment. Emission and excitation half band widths of 10 and $3 \mathrm{~nm}$, respectively, were employed and a Corning 2-61 cutoff filter $(5,33$, and $72 \%$ transmission at 605,615 , and $625 \mathrm{~nm}$, respectively) blocked the light beam entering the emission monochromator. The $F_{685}$ chl a fluorescence spectra were corrected by dividing the measured spectra by the rhodamine B spectrum of the instrument (Yguerabide 1968).

For measurements at $730 \mathrm{~nm}\left(\mathrm{~F}_{730}\right)$, emission and excitation half band widths were 10 and $5 \mathrm{~nm}$ respectively. A blocking Hoya R- 72 cutoff filter $(5,33$, and $72 \%$ transmission at 705,718 , and $740 \mathrm{~nm}$, respectively) was placed in front of the emission monochromator. The spectrofluorometer was set in the energy mode. System spectral correction was provided by the thermopile method (Argauer \& White 1964). The configuration of the thermopile (Kettering Scientific Res. model 68) was such that the light probe fit snugly within the spectrofluorometer's cuvette holder with its detector positioned at the focus of the exciting beam. Light-energy values were recorded at $5 \mathrm{~nm}$ intervals. These values, after conversion to relative quantum flux units (energy times wavelength), were interpolated linearly at $1 \mathrm{~nm}$ intervals. The resulting correction spectrum resembled closely that reported earlier for a similar $150 \mathrm{~W}$ xenonarc light source (Yguerabide 1968). The raw $F_{730}$ spectra were digitized at $1 \mathrm{~nm}$ intervals into a microcomputer and were divided by the thermophile correction spectrum to obtain the corrected $F_{730}$ chl a fluorescence excitation spectra. 


\section{RESULTS AND DISCUSSION}

Action spectra for excitation of $F_{685}$ and $F_{730} \mathrm{~nm} \mathrm{chl}$ a fluorescence and for modulated $\mathrm{O}_{2}$ production in each of the algal pigment types are given in Figs. 1 to 5, the curves being arbitrarily scaled to each other and, in part, overlapping. Plotted in this manner, it is readily apparent that for a given alga all action spectra are qualitatively similar in general shape. Major variations between species are relatable to the differing spectral prominences of their dominant accessory pigments (except for Porphyridium cruentum; see Table 1 in Neori et al. 1986).

In the case of Chaetoceros gracilis (Fig. 3) and Chroomonas sp. (Fig. 5) agreement in positions of the red peaks is less satisfactory and for most algae (Figs. 2 to 5) spurious peaks near 468 and $490 \mathrm{~nm}$ are evident in the $F_{730}$ spectra. Some of these curve deviations could

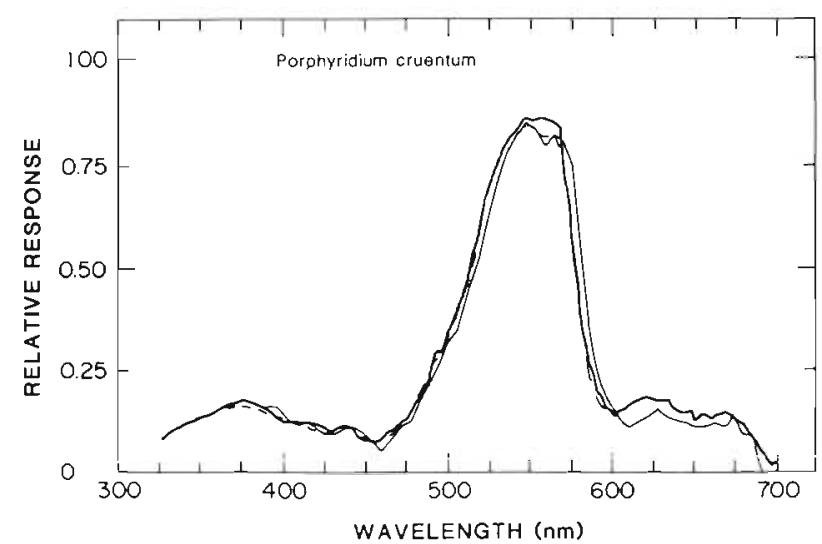

Fig. 1. Porphyridium cruentum. Action spectra for chlorophyll a fluorescence at $685 \mathrm{~nm}\left(\mathrm{~F}_{685}\right)$ (dashed line); chlorophyll a fluorescence at $730 \mathrm{~nm}\left(\mathrm{~F}_{730}\right)$ (heavy line $)_{i}$ and photosystem II photosynthetic $\mathrm{O}_{2}$ evolution (light line). Note that the $685 \mathrm{~nm}$

fluorescence spectrum does not extend beyond $610 \mathrm{~nm}$

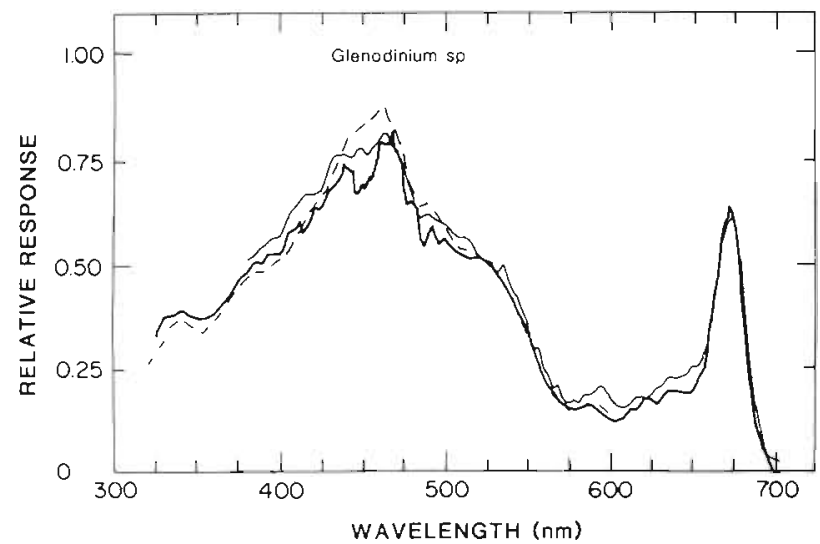

Fig. 2. Glenodinium sp. Action spectra for chlorophyll a fluorescence at $685 \mathrm{~nm}\left(F_{685}\right)$ (dashed line); chlorophyll a fluorescence at $730 \mathrm{~nm}\left(\mathrm{~F}_{730}\right)$ (heavy line); and photosystem II photosynthetic $\mathrm{O}_{2}$ evolution (light line). Note that the $685 \mathrm{~nm}$ fluorescence spectrum does not extend beyond $610 \mathrm{~nm}$

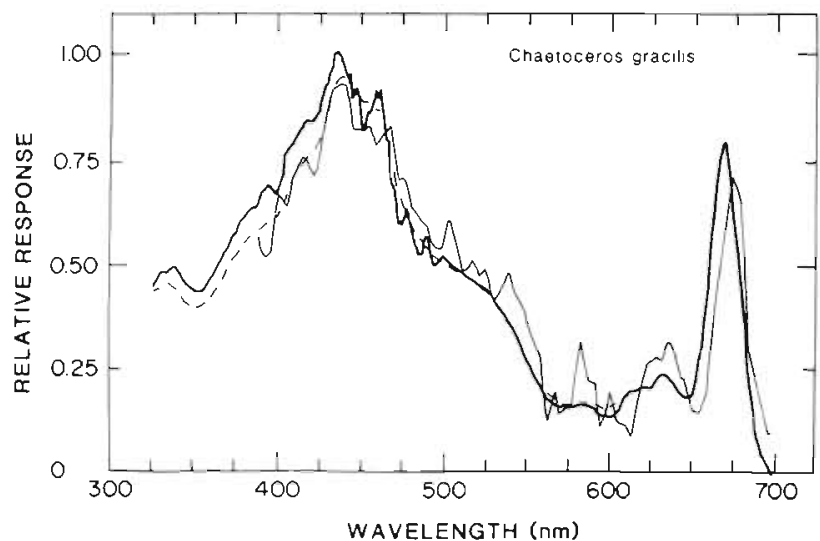

Fig. 3. Chaetoceros gracilis. Action spectra for chlorophyll a fluorescence at $685 \mathrm{~nm}\left(\mathrm{~F}_{685}\right)$ (dashed line); chlorophyll a fluorescence at $730 \mathrm{~nm}\left(\mathrm{~F}_{730}\right)$ (heavy line); and photosystem II photosynthetic $\mathrm{O}_{2}$ evolution (light line). The photosynthetic curve is the average of 2 spectra. Note that the $685 \mathrm{~nm}$

fluorescence spectrum does not extend beyond $610 \mathrm{~nm}$

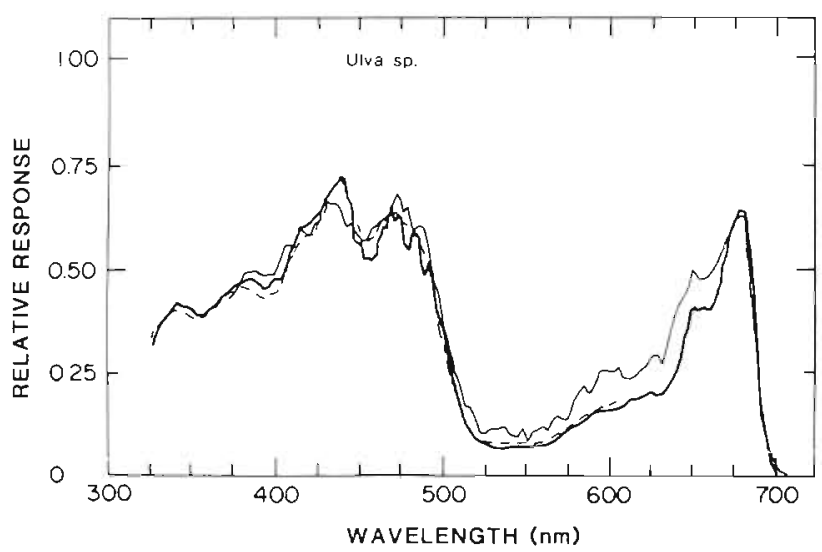

Fig. 4. Ulva sp. Action spectra for chlorophyll a fluorescence at $685 \mathrm{~nm}\left(\mathrm{~F}_{685}\right)$ (dashed line); chlorophyll a fluorescence at $730 \mathrm{~nm}\left(\mathrm{~F}_{730}\right)$ (heavy line); and photosystem II photosynthetic $\mathrm{O}_{2}$ evolution (light line). Note that the $685 \mathrm{~nm}$ fluorescence spectrum does not extend beyond $610 \mathrm{~nm}$

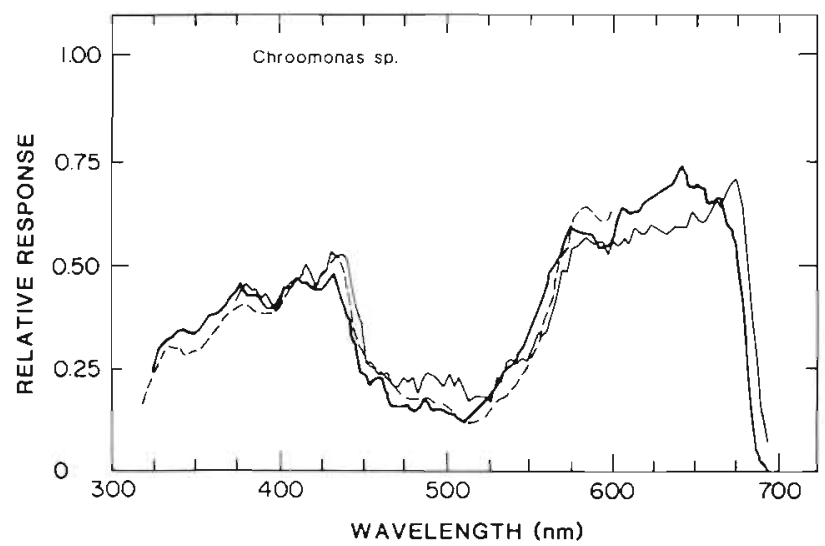

Fig. 5. Chroomonas sp. Action spectra for chlorophyll a fluorescence at $685 \mathrm{~nm}\left(\mathrm{~F}_{685}\right)$ (dashed line); chlorophyll a fluorescence at $730 \mathrm{~nm}\left(\mathrm{~F}_{730}\right)$ (heavy line); and photosystem II photosynthetic $\mathrm{O}_{2}$ evolution (light line). Note that the $685 \mathrm{~nm}$ fluorescence spectrum does not extend beyond $610 \mathrm{~nm}$ 
arise from the use of very thin suspensions for the $\mathrm{O}_{2}$ measurements (low signal to noise ratio) and inadequacies in resolving corrections for actinic light at wavelengths of very sharp emission bands of the xenon arc lamp. However the possibility cannot be disregarded that real, albeit small, differences exist between the $\mathrm{O}_{2}$ and the fluorescence spectra in some species.

The spectra for Porphyridium cruentum (Fig. 1) show excellent agreement with each other at all wavelengths and are in good agreement with the action spectrum for modulated $\mathrm{O}_{2}$ evolution reported by Ley \& Butler (1977) employing comparable instrumentation. All 3 action spectra closely resemble the absorption spectrum of the biliprotein mixture present, which is dominated by B-phycoerythrin (Haxo et al. 1955). The close similarity between the $F_{730}$ spectrum and the $F_{685}$ spectrum further suggests there is very little, if any, spectral contribution to $F_{730}$ by PSI-absorbed light. This appears to be the general situation in rhodophytes (Larkum \& Barrett 1983). An exception was reported by Fork et al. (1982) for Porphyra perforata (an observation we have confirmed) in that the $F_{730}$ excitation spectrum includes a significant spectral contribution from PSI absorption.

In the dinoflagellate Glenodinium sp. (Fig. 2) and the diatom Chaetoceros gracilis (Fig. 3), broadened activity across the spectral interval 490 to $560 \mathrm{~nm}$ is seen in all action spectra, reflecting major absorption by the characteristic accessory xanthophylls present, peridinin and fucoxanthin, respectively. In Glenodinium sp. the correspondence in peak positions and curve shapes in regions of chl $a$ and chl $c$ absorption are particularly evident in both $\mathrm{O}_{2}$ and $\mathrm{F}_{730}$ spectra. In Chaetoceros gracilis the $\mathrm{O}_{2}$ action spectrum was noisy and could not be improved without using undesirably dense cell mounts on the electrode. The overall shape of this curve, however, resembles closely a smoothed curve for $\mathrm{O}_{2}$ production we reported earlier for this species (Fig. 3b in Neori et al. 1986). Both $\mathrm{O}_{2}$ action spectra correspond fairly well with the $F_{730}$ and $F_{685}$ curves, except that the chl a peak at $673 \mathrm{~nm}$ in the $F_{730}$ spectrum is blue-shifted to $665 \mathrm{~nm}$.

In the chlorophyte Ulva sp. (Fig. 4), the agreement between the fluorescence and the $\mathrm{O}_{2}$ spectra is not as good as in Glenodinium sp. Although peak and shoulder features of these spectra correspond to major absorptions by chl $a_{1} c h l b$ and carotenoids, the relative magnitudes of the $\mathrm{F}_{730}$ and the $\mathrm{O}_{2}$ spectra differ by as much as $30 \%$. In the phycocyanin-rich cryptomonad Chroomonas sp. (Fig. 5), excellent agreement was observed in curve shapes and location of activity peaks through the spectral interval 320 to $580 \mathrm{~nm}$ but divergences are evident at longer wavelengths. As plotted, light absorbed by phycocyanin-645 (550 to $670 \mathrm{~nm}$ ) appears to be more effective in generating $\mathrm{F}_{730}$ fluorescence than oxygen evolution; further, the $\mathrm{O}_{2}$ action spectrum showed a distinct peak at $678 \mathrm{~nm}$ which was not evident in the fluorescence excitation spectrum. The basis for these effects has not been resolved.

We find it significant that in all 5 species the $F_{730}$ spectra reveal the important features of pigment activity above $610 \mathrm{~nm}$ which also appear in the $\mathrm{O}_{2}$ spectra. This includes intervals of prominent contributions to absorption by phycocyanin in Porphyridium cruentum (610 to $660 \mathrm{~nm}$ ) and Chroomonas sp. (610 to $670 \mathrm{~nm})_{i}$ chl $c$ in Glenodinium sp. and Chaetoceros gracilis (ca 610 to $640 \mathrm{~nm}$ ); chl $b$ in Ulva (ca 610 to $660 \mathrm{~nm}$ ), and chl $a$ in all algae (650 to $700 \mathrm{~nm}$ )

The good correlation between the shapes of the $\mathrm{O}_{2}$ and the $\mathrm{F}_{730}$ spectra suggests that the pigments which spectrally dominate $F_{730}$ chl a fluorescence at room temperatures in these algae are similar to those associated with PS II. In this connection it is noteworthy that the earlier studies by Goedheer $(1965,1981)$ on chlorophyll fluorescence at room temperature in e.g. Anaebaena and Chlorella were interpreted as showing participation of PS II pigments in $F_{715}$ emission. The extent to which this relationship is dependent upon growth conditions is an important consideration, particularly in field applications. We are encouraged, however, that in the several species we have examined, the relationship appears to persist in cells grown under varying irradiance and nutrient regimes (Neori 1986).

Although the molecular origins of $\mathrm{F}>710$ emission remain uncertain (Wong \& Govindjee 1981, Peyriere et al. 1984, Wendler et al. 1984), our results indicate that measurement of $F_{730}$ can be used to gain important and otherwise unobtainable information on the extended spectral characteristics of photosynthetic potential in natural and laboratory populations of algae. For instance, it would not be feasible to document the photosynthetic action spectra of natural populations as a function of depth in ocean profiles by using the modulated $\mathrm{O}_{2}$ electrode system. As presently employed, this method involves specialized and sensitive equipment, highly trained personnel, a requirement for genthe concentration of phytoplankton from large water volumes and problems with intolerance of some algal species to the bare platinum electrode. However, $F_{730}$ spectra can be measured with commercially available instrumentation, on station, at a rate of several samples per hour and with relatively little training.

The results of such a profile can give information on the spectral shapes of photosynthetic activity associated with absorption by major pigments and their change with depth or with time. When compared to the in vivo absorption spectra of the same samples (which can be measured on the same filter as in Neori et al. 1984), one can quantitatively assess the amount of light 
that is absorbed by photosynthetically active pigments compared to total light absorption. It should be emphasized, however, that the 'overlap' of the 3 spectra (Figs 1 to 5 ) reflects only the relative spectral response, and not the magnitude of each signal. Thus, integration of the area under the $F_{730}$ curve cannot be arbitrarily set to equal the rate of oxygen production. Quantification of the signals has not been attempted and might prove difficult in the present instrumental arrangement. However, with the methods developed by Mitchell \& Kiefer (1984) and Mitchell (1987), it should be possible to estimate relative photosynthetic quantum yields of the samples

It is evident from our data that measurements of chlorophyll a fluorescence may offer a useful alternative to spectral measurements of PS II activity by modulated $\mathrm{O}_{2}$ production. The $\mathrm{F}_{685}$ excitation spectra offer superior sensitivity, methodological simplicity, and a rather established correlation with PS II photosynthetic activity, but do not assess the orange to red region of the action spectrum. The $F_{730}$ chl fluorescence action spectra, on the other hand, combine the methodological advantages of fluorescence with the broader spectral range of the modulated $\mathrm{O}_{2}$ electrode technique. In future applications the resolution, accuracy and sensitivity of the $\mathrm{F}_{730}$ fluorescence method could be improved by the use of a more sensitive thermopile, a photomultiplier having an enhanced far-red response and a high-resolution data acquisition system.

Acknowiedgements. This work was supported in part by NSFDPP grant 83-18465 to O.H.H., NASA contract via BSI \# 3734, DOE contract DEASO3-82ER60031, and a grant to A.N., O.H.H. and F.T.H. from the Foundation for Ocean Research. We thank B. B. Prézelin and D. S. Berns, respectively, for providing isolates of Glenodinium sp. and Chroomonas sp.; $\mathrm{J}$ Lance and M. Alden for help in culturing; and M. D. Kamen for the loan of the special thermopile. We are further indebted to D. C. Fork and anonymous reviewers for insightful comments during preparation of the final manuscript.

\section{LITERATURE CITED}

Argauer, R. J., White, C. E. (1964), Fluorescence compounds for calibration of excitation and emission units of spectrofluorometer. Analyt. Chem. 36: 368-371

Dutton, H. J., Manning, W. M., Duggar, B. M. (1943). Chlorophyll fluorescence and energy transfer in the diatom Nitzschia closterium. J. phys. Chem. 47: 308-313

Duysens, L. N. M. (1952). Transfer of excitation energy in photosynthesis. Ph. D. thesis, State University of Utrecht, The Netherlands

Fork, D. C., Öquist, G., Hoch, G. E. (1982). Fluorescence emission from photosystem I at room temperature in the red alga Porphyra perforata. Plant Sci. Lett. 24: 249-254

Goedheer, J. C. (1965). Fluorescence action spectra of algae and bean leaves at room temperature. Biochem. Biophys. Acta 102: 73-89
Goedheer, J. C. (1972). Fluorescence in relation to photosynthesis. Ann. Rev. Plant Physiol 23: 87-112

Goedheer, J. C. (1981). Comparison of the long-wavelength chlorophyll fluorescence in various green and blue-green algae and diatoms. Photosynth. Res 2: 49-60

Govindjee, Yang, L. (1966). Structure of the red fluorescence band in chloroplasts. J. gen. Physiol. 49: 763-780

Haxo, F. T. (1985). Photosynthetic action spectrum of the coccolithophorid, Emiliania huxleyi (Haptophyceae): 19hexanoyloxyfucoxanthin as antenna pigment. J. Phycol. 21: $282-287$

Haxo, F. T., O'Eocha, C., Norris, P. (1955). Comparative studies of chromatographically separated phycoerythrins and phycocyanins. Arch. Biochem. Biophys. 54: 162-173

Joliot, P., Joliot, A. (1968). A polarographic method for the detection of oxygen production and reduction of Hill reagents by isolated chloroplasts. Biochem. Biophys. Acta 153: 635-652

Larkum, A. W. D., Barrett, J. (1983). Light harvesting processes in algae. In: Woolhouse, H. W. (ed.) Advances in botanical research, Vol. 10. Academic Press, London, p. $1-219$

Ley, A. C., Butler, W. L. (1977). The distribution of excitation energy between photosystem I and photosystem II in Porphyridium cruentum. In: Miyachi, S., Katoh, S., Fujita, Y., Shibata, K. (eds.) Photosynthetic organelles. Japanese Soc. Plant Physiologists, Center for Acad. Publ., Tokyo, p. $33-46$

Loeblich, A. R. III (1975). A seawater medium for dinoflagellates and the nutrition of Cachonina niei. J. Phycol, 11: $80-86$

Lüning, K., Dring, M. J. (1985). Action spectra and spectral quantum yield of photosynthesis in marine macroalgae with thin and thick thalli. Mar. Biol. 87: 119-129

Mitchell, B. G., Kiefer, D. A. (1984). Determination of absorption and fluorescence excitation spectra for phytoplankton. In: Holm-Hansen, O., Bolis, I., Gilles, $\mathrm{R}$. (eds.) Viarine phytoplankton productivity. Springer-Verlag, Berlin, p. $157-169$

Mitchell, B. G. (1987). Ecological implications of variability in marine particulate absorption and fluorescence excitation spectra. Ph. D. thesis, University of Southern California

Neori, A. (1986). Excitation spectra of chlorophyll a fluorescence in vivo: their correlation with photosynthetic action spectra and their use in the study of algal photoadaptation. Ph. D. thesis, University of California, San Diego

Neori, A., Holm-Hansen, O., Mitchell, B. G., Kiefer, D. A. (1984). Photoadaptation in marine phytoplankton: changes in spectral absorption and excitation of chlorophyll a fluorescence. Plant Physiol. 76: 518-524

Neori, A., Vernet, M., Holm-Hansen, O., Haxo, F. T. (1986). Relationship between action spectra for chlorophyll a fluorescence and photosynthetic oxygen evolution in algae. J. Plankton Res. 8: 537-548 (see corrigendum in J. Plankton Res. 8: 1009-1010)

Owens, T. G., Gallagher, J. C., Alberte, R. S. (1987). Photosynthetic light-harvesting function of violaxanthin in Nannochloropsis spp. (Eustigamatophyceae). J. Phycol. 23: 79-85

Peyriere, M., Caron, L., Jupin, H. (1984). Pigment complexes and energy transfers in brown algae. Photosynthetica 18: 184-191

Prézelin, B. B., Ley, A. C., Haxo, F. T (1976). Effects of growth irradiance on the photosynthetic action spectra of the marine dinoflagellate, Glenodinium sp. Planta (Berl.) 130: 251-256

Wendler, J., Haehnel, W., Holzwarth, A. R. (1984). Time- 
resolved picosecond fluorescence spectra of the antenna chlorophylls in the green alga Chlorella vulgaris. In: Auston, D. H., Eisenthal, K. B. (eds.) Ultrafast phenomena IV. Springer-Verlag, Berlin, p. 503-505

Wong, D., Govindjee (1981). Action spectra of cation effects on the fluorescence polarization and intensity in thylakoids at room temperature. Photochern. Photobiol. 33: 1.03-108
Yentsch, C. S., Yentsch, C. M. (1979). Fluorescence spectral signatures: the characterization of phytoplankton populations by the use of excitation and emission spectra. J. mar Res. 37: 471-483

Yquerabide, J. (1968). Fast and accurate method for measuring photon flux in the range $2500-6000 \AA$. Rev. Sci. Instr 39: 1048-1052

This article was submitted to the editor; it was accepted for printing on March 4, 1988 